\title{
DIÁLOGOS ENTRE MUSEU E ESCOLA: RELAÇõES POSSÍVEIS NO CENÁRIO DE PESQUISA ATUAL
}

\section{DIALOGUES BETWEEN MUSEUM AND SCHOOL: POSSIBLE RELATIONS IN THE CURRENT RESEARCH SCENARIO}

\author{
CAGLIARI, Angela Zanotelli ${ }^{1}$ \\ ZUCOLOTTO, Andréia Modrzejewski
}

\begin{abstract}
RESUMO
Este estudo tem como objetivo conhecer e analisar artigos científicos que discorrem sobre as relações entre museu e escola. $O$ presente texto trata-se de uma revisão bibliográfica baseada na literatura especializada recente, dentro do período temporal de 2007 a 2017, na qual procurou-se identificar, descrever e analisar as produções científicas em formato de artigo mais atuais disponíveis em língua portuguesa. Os artigos analisados buscam interlocuções teóricas e práticas entre museu e escola, a partir de diferentes vieses. Esta revisão mirou publicações que articulassem o espaço museológico e o espaço escolar na expectativa de desvendar o atual contexto de investigação científica relativo à educação formal e seus possíveis diálogos com a museologia. Conclui-se que ainda há poucos estudos realizados na área e o principal foco das pesquisas abordadas está no museu enquanto locus social, logo educativo. Destaca-se a importância de realizar outras investigações em idioma português sobre o tema a fim de colaborar para o desenvolvimento da área de museologia associada à educação.
\end{abstract}

PalaVRas-ChaVe: Museu; Escola; Museologia; Educação; Produção científica.

\section{ABSTRACT}

This study aims to know and analyze scientific articles that discuss the relations between museum and school. The present text is a bibliographical review based on the recent specialized literature, within the time period from 2007 to 2017, in which it was sought to identify, describe and analyze the scientific productions in the most current article format available in Portuguese language. The analyzed articles seek theoretical and practical interlocutions between museum and school, from different points of view. This review looked at publications that articulated the museological space and the school space in the expectation of unveiling the current context of scientific research related to formal education and its possible dialogues with museology. It is concluded that there are still few studies

\footnotetext{
${ }^{1}$ Mestranda em Educação Profissional e Tecnológica no Instituto Federal de Ciências e Tecnologia do Rio Grande do Sul (IFRS). Licenciada em Artes Visuais (UFRGS), docente do Instituto Federal de Ciências e Educação do Rio Grande do Sul (IFRS). Porto Alegre, Brasil. e-mail: angelazc@gmail.com

${ }^{2}$ Doutora em Educação (PUCRS), docente do Instituto Federal de Ciências e Tecnologia do Rio Grande do Sul (IFRS). Porto Alegre, Brasil. e-mail: andreia.zucolotto@poa.ifrs.edu.br
} 
DOI: $10.12957 / \mathrm{e}-\mathrm{mosaicos} .2019 .41203$

carried out in the area and the main focus of the researches studied is in the museum as a social locus, thus educational. It is important to carry out other Portuguese-language research on the subject in order to collaborate in the development of the area of museology associated with education.

KeYWORDS: Museum; School; Museology; Education; Scientific production.

\section{INTRODUÇÃO}

Uma função importante de uma instituição museológica é a educativa. O patrimônio cultural é a problemática do museu, e as ações educativas que podem se materializar através de exposições, por exemplo, são formas de abordar a cultura material e imaterial produzida pelos seres humanos. O museu é um lugar educativo no qual o processo de aprendizagem se dá pelos objetos expostos (CURY, 2005). Portanto, a fim de desenvolver este estudo de revisão envolvendo museu e escola, tomaremos aqui a afirmativa que museu e educação caminham juntos para o desenvolvimento da cidadania e da transformação social (FREIRE, 1988, 1996; SANTOS, 2002). Ambas as áreas de estudo são interdisciplinares, e por assim serem, possuem uma grande produção de conhecimento que abarca diversas problemáticas por diversos vieses.

Aqui optamos por abordagens que relacionam a prática educativa no museu e na escola, pois nossa motivação surgiu da necessidade de conhecer os estudos mais recentes que tecem diálogos entre museu e escola na medida em que acreditamos que este é um tema contemporâneo na educação brasileira. A revisão da literatura se insere em uma pesquisa mais ampla, do mestrado profissional em Educação Profissional e Tecnológica do Instituto Federal do Rio Grande do Sul, na qual almejase investigar as relações entre o ensino escolar e o museu como modos de educação integral. Buscamos, através da revisão de artigos publicados, compreender algumas questões, como: o que é e como é considerada, pela comunidade científica de língua portuguesa, a relação entre museu e escola? Quais são as possibilidades de diálogo entre a instituição museológica e a instituição escolar? Sob quais perspectivas teóricas o tema museu e escola vem sendo estudado?

Na tentativa de buscar respostas, ou ainda, novas perguntas a esse respeito, selecionamos artigos revisados por pares, disponíveis no Portal de Periódicos da Capes, publicados em língua portuguesa entre os anos de 2007 e 2017. Os artigos de Braga (2015), Buchmann (2014), Freitas e Siman (2015), Oliveira (2013), Pacheco (2010), Pereira e Carvalho (2010) e Vergara (2016) foram analisados a partir da concepção de educação transformadora de sujeitos e de seu status quo, como fomentadora de outras visões de mundo, no desenvolvimento da cidadania e da autonomia. Escolhemos Paulo Freire (1996; 1988) como fio condutor, pois acreditamos que, dada a realidade brasileira, Freire contempla as principais questões para que possamos estabelecer diálogo entre museu e escola, além de ser citado por alguns dos artigos apresentados como referência para a educação museológica 
DOI: $10.12957 / \mathrm{e}-\mathrm{mosaicos} .2019 .41203$

(BUCHMANN, 2014; PACHECO, 2010; VERGARA, 2016) e como peça-chave no desenvolvimento da renovação da museologia com função social (ALVES; REIS, 2013).

Na primeira parte a metodologia mencionamos quais descritores foram usados, bem como os critérios de inclusão e de exclusão e os resultados obtidos. $\mathrm{Na}$ continuidade, os artigos escolhidos são analisados sob a perspectiva dialógica entre as já citadas áreas de interesse, especialmente a partir de ideias freireanas e de Maria Célia Santos, museóloga brasileira que faz uso das ideias de Freire em sua prática educativa em museus. Estes autores foram selecionados por entenderem a educação e a museologia como processos contínuos, da e na sociedade, que contribuem para o desenvolvimento integral dos sujeitos. Com essa perspectiva, endossamos a importância da relação do museu com a escola e vice-versa para a formação de autonomia e cidadania.

Por fim, destacamos os aspectos mais importantes abordados nas pesquisas já realizadas e sinalizamos possíveis horizontes para a continuidade de investigações no âmbito da museologia e da educação. Tais campos, apesar de seu crescente desenvolvimento ainda são pouco explorados pela comunidade científica de língua portuguesa.

\section{Metodologia}

Quanto à metodologia, trata-se de um estudo qualitativo, exploratório, cujo procedimento técnico escolhido foi a análise de artigos de autores em língua portuguesa. Optou-se pela pesquisa somente neste idioma pelo desejo de conhecer fontes produzidas em nosso idioma e compreender como é vista a relação entre museologia e educação pelo olhar dos pesquisadores, que são, em grande parte, brasileiros. Foram selecionados artigos publicados com revisão por pares, dentro de uma década específica (de 2007 a 2017), disponíveis no Portal de Periódicos da Capes. Os descritores escolhidos incialmente foram "exposição e escola", "expografia e educação", "expografia e educação", "museologia e escola". Nenhum destes termos acusou resultados, sendo necessário alterações nas palavras buscadas. 0 fato de não serem encontrados artigos com esses termos já é um indicativo da pouca produção científica a respeito da associação entre museu e escola no mundo acadêmico.

Desse modo, alteramos os descritores e identificamos para "museologia e educação" 33 resultados, "museologia e escola" 29 artigos encontrados, "museu e educação", 350 resultados e "museu e escola", 369 artigos. Obtivemos, no total, 781 resultados, com grande percentual de repetições, aos quais foram aplicados os seguintes critérios de seleção e exclusão: a leitura do título, em seguida adequação das palavras-chave ao tema em estudo e a leitura do resumo. Por fim, foram selecionados sete artigos para análise, os quais discorrem sobre o escopo de nosso 
DOI: $10.12957 / \mathrm{e}-\mathrm{mosaicos} .2019 .41203$

estudo, sendo que foram escritos por pesquisadores de diversas áreas de formação das disciplinas humanas, sendo a história e as ciências sociais como predominantes.

\section{RESULTADOS}

A fim de iniciar a amostragem de resultados do estudo, vamos situar os conceitos de museu e de museologia considerados neste texto, pois ambos os termos possuem muitas definições e aqui nos interessa aquela que toca no social. 0 termo "museu" passou por diversas concepções ao longo dos séculos, de templo de musas em sua origem grega, até a ideia de museu virtual na atualidade. $O$ conceito de museu adotado neste estudo é aquele entendido como instrumento concebido por homens e mulheres para a compreensão da interdependência entre a humanidade e a realidade, entre o social, o natural e o estético e o desenvolvimento humano associados aos processos museológicos de conservação, pesquisa e comunicação, ou seja, o museu com função social (DESVALLÉES; MAIRESSE, 2013; SANTOS, 2002). Para Cury (2013), a atuação do museu assume uma perspectiva da cidadania cultural e enquanto instituição não pode ser neutra, pois defende pontos de vista, posições políticas, assim como a instituição escolar que tem em seu horizonte a formação de cidadãos críticos e livres.

A partir da segunda metade do século XX começa-se a questionar a missão social dos museus e a partir disso, torna-se válido refletir sobre como a museologia pode interferir nas práticas sociais, e a prática educativa afirma o caráter social e interdisciplinar dos museus. O termo museologia é compreendido como disciplina humana aplicada, em formação e em constante renovação, que pode ser entendida como o estudo crítico da instituição museu e suas relações, e especialmente da relação entre homens e mulheres e suas interações com as suas realidades específicas (DESVALLÉES; MAIRESSE, 2013). Cury (2005) adiciona que a museologia é a área do conhecimento que conecta o campo social ao patrimonial, permitindo a sua interação de forma intencional.

A museologia ainda é um campo de estudos em consolidação no país. Não almejamos adentrar na história da área, apenas pontuar que os cursos superiores em museologia são relativamente recentes no Brasil. Segundo levantamento realizado pelo Conselho Federal de Museologia (COFEM) ${ }^{3}$, no país existem treze cursos em nível de graduação e quatro em nível de pós-graduação, todos em universidades públicas. No Brasil, a história da museologia enquanto área do conhecimento acadêmico começa a transformar-se a partir de um importante evento ocorrido em Santiago do Chile, chamado Mesa Redonda de Santiago, em 1972. O evento teve como principal visão norteadora a filosofia de Paulo Freire e embasou a Nova Museologia, vertente que afirma a função social e o potencial transformador do museu e de seus públicos por meio da interação entre o patrimônio cultural e a

3 Conselho Federal de Museologia. Formação em museologia. Disponível em: http://cofem.org.br/about/formacao/ Acesso em: 15 de janeiro de 2019. 
DOI: $10.12957 / \mathrm{e}-\mathrm{mosaicos} .2019 .41203$

sociedade. Corroborando com o desenvolvimento da museologia brasileira e sua associação à educação, localizamos o artigo de Freitas e Siman (2015) no qual as pesquisadoras lançam luz ao Museu de Quilombos e Favelas Urbanas (Muquifu) como um estudo de caso do museu como uma forma de resistência às reformas urbanas na cidade de Belo Horizonte, sendo ele classificado como museu comunitário. Para que compreendamos o caminho desenvolvido até a ideia da própria comunidade fazer o museu, as autoras realizam um apanhado histórico das primeiras instituições museológicas do Brasil.

Freitas e Siman (2015), de forma crítica, revelam que os objetivos das primeiras e mais tradicionais instituições museológicas do país, como o Museu Mariano Procópio (MMP) em Minas Gerais e o Museu Histórico Nacional (MHN), no Rio de Janeiro residiam em valorizar a cultura aristocrata e elitista. É apenas nos anos 1970, em consonância com a Mesa Redonda de Santiago, que as instituições museológicas começam a lançar suas vistas para além da valorização da aristocracia e da idealização europeia. Mesmo que ainda sujeitos à conjuntura política do país durante a ditatura militar, esses espaços museológicos iniciam um processo de compreensão e expansão da função social dos museus e do patrimônio cultural que vai culminar nas proposições levantadas em 1972 no Chile, a já mencionada Mesa Redonda de Santiago, tendo a educação freireana como principal referência para transformar o museu em espaço social.

Inaugura-se então a chamada Nova Museologia, linha de atuação que defende o poder transformador e de transformação do museu enquanto instituição, a qual, assim como a escola, só tem razão de existir se for pelos sujeitos e pelos coletivos que nela interferem. É o início de uma batalha contra a hegemonia da elite social, que historicamente sempre foi público privilegiado pelos museus. As autoras Freitas e Siman (2015) trazem o caso do Museu de Quilombos e Favelas Urbanas (Muquifu) como um exemplo de espaço cultural na e da periferia, onde os moradores da região podem afirmar suas histórias, no qual se apropriam da linguagem museológica - tão elitizada - e ressignificam suas narrativas e memórias, apesar da gentrificação urbana, vislumbrando um horizonte de autonomia (FREIRE, 1996).

Dados os exemplos, defendemos que, além de comunitário, podemos dizer que, segundo Rangel (2015), os museus que interagem intencionalmente com grupos específicos da sociedade e envolvem-se na e para suas comunidades, encaminham-se para o que chama-se de museu integral e integrado, como proposto pelo evento Mesa Redonda de Santiago. Nos parece esse ser um modelo muito educativo, à medida que leva em consideração a comunidade como sujeito do e para o museu, onde se pode exercer a cidadania e a afirmação de identidades excluídas, tendo o museu um papel de transformar realidades quando é apropriado por coletivos sociais.

No mesmo caminho social da pesquisa acima, Oliveira (2013) em seu artigo "O museu como instrumento de reflexão social" aborda a Nova Museologia, desde a conferência da Unesco no Rio em 1958 até a Declaração de Caracas, de 1992, para 
DOI: $10.12957 / \mathrm{e}-\mathrm{mosaicos} .2019 .41203$

afirmar o museu como espaço educativo do ser humano individual e coletivo. A autora compreende o fator social como papel fundamental dos espaços museais na educação da comunidade, que colabora para a diminuição das barreiras entre o conhecimento e o museu. Em outras palavras, o museu é um potente fomentador da democratização social, especialmente nos formatos de museu integral e museu aberto, conceitos que veem o museu como um elemento vivo dentro das diversas dinâmicas sociais das cidades. Oliveira (2013) questiona a ideia de museu para todos, assim como a escola para todos, afirmando que esses modelos são aparentemente inclusivos, revoltos na ideia democrática para todos, porém, acabam por homogeneizar a educação devido ao distanciamento entre as políticas educativas/museais e suas capacidades de as por em prática.

Para fazer diferente, Oliveira (2013) sugere a ideia de equidade como sendo mais democrática a partir de exemplos de instituições museológicas na Espanha, Inglaterra e Estados Unidos. Segundo a autora, os museus que conseguem trabalhar com a ideia de equidade, através de suas ações educativas, promovem exposições que fornecem novas visões de mundo porque focam suas mostras em abordagens sociais contemporâneas próximas das pessoas, ou seja, ativam o interesse de seu público e alcançam seu potencial educativo. Nesse sentido, apesar de não utilizar as ideias de Paulo Freire, a historiadora se aproxima da noção de educação crítica do educador e da museóloga Maria Célia Santos.

Ambos os artigos de Freitas e Siman (2015) e Oliveira (2013) realizam um apanhado histórico da museologia como se para dar sentido ao museu social que tem se preconizado na atualidade. O senso comum ainda carrega consigo a ideia de museu como espaço sagrado restrito aos privilegiados da elite, no qual apenas é bem-vindo quem domina os modos de ser em um museu. Por isso, é salutar a contextualização do desenvolvimento da Nova Museologia, contribuindo para o conhecimento e divulgação da área.

A relação museu-escola, a expansão do espaço educativo, ou interação entre museu e escola é defendida por Santos (2002) como aquela que seja baseada na ação e na reflexão críticas através de métodos e de técnicas que façam sentido para o grupo de pessoas envolvidas, devendo sempre serem contextualizados e em constante avaliação. A educação e a museologia são processos condicionados social e historicamente, resultam das ações dos seres humanos sobre e no mundo. Nesse sentido, podemos pensar sobre a linguagem do museu em relação à linguagem da escola, aos tempos, aos espaços.

Pereira e Carvalho (2010) no texto "Sentido dos tempos na relação museu/escola" discutem a relação entre o museu e a escola e os diferentes tempos presente nesses espaços. Coloca o museu como um lugar com intenções educativas, que através de suas exposições cria oportunidades de compreender a função dos objetos expostos em outra relação de espaço-tempo, que é condicionado à capacidade criadora dos visitantes, no caso dos estudantes. Portanto, existe uma relação de trânsito entre o estudante e a exposição, sendo ela uma experiência 
DOI: $10.12957 / \mathrm{e}-\mathrm{mosaicos} .2019 .41203$

educativa que, deslocada do espaço-tempo da escola, só pode ser consumada se fizer relação com o que o aluno conhece, mas de modo algum significa aceitar o que é mostrado sem criticidade. A exposição precisa fazer sentido, ter significado, ter linguagem que permita ser reconhecida e interpretada.

Para os autores, a ida ao museu e a uma exposição com objetos mostrados de forma temporalmente fragmentados (uma exposição histórica) não podem ser entendidos pelos docentes como uma possibilidade de aprendizagem total, e sim uma oportunidade de sensibilização conectada ao processo educativo já iniciado em sala de aula, desse modo há sentido e significado educativo na ida ao museu. Santos (2002) afirma que as ações museológicas só podem atingir os objetivos de transformação social e exercício da cidadania se forem associadas à dimensão educativa, porque assim como a educação formal, os processos de um museu também são dinâmicos, resultantes da ação e reflexão dos sujeitos participantes do processo. Por conseguinte, o papel do educador é de extrema importância para mediar a relação educativa antes e durante a visita ao museu.

Ao entendermos que processos educativos, independentemente do local onde ocorrem, não se esgotam, pois sabendo que somos incompletos, podemos ser aprendentes pela vida toda. Paulo Freire em sua Pedagogia da Autonomia, nos diz que uma das funções essenciais da escola é sistematizar o conhecimento, trabalhar de forma crítica as coisas e os acontecimentos e por consequência, sua comunicabilidade (FREIRE, 1996). Em uma reflexão crítica sobre a função do museu, Pacheco (2010) relata a experiência de pesquisa e montagem de exposição e ações educativas no Memorial da Universidade Federal Rural de Pernambuco (UFRPE). A exposição "UFRPE: ensino, pesquisa e extensão" foi desenvolvida para refletir sobre a produção de discursos historiográficos e divulgação de narrativas da memória da Universidade, tanto a memória institucional (aquela oficial, documentada) quanto a memória individual e a coletiva, as quais constituem uma identidade social.

O autor questiona o museu enquanto espaço de exposição e não de conhecimento, o qual fortalece um passado institucional sem o elemento humano, dos sujeitos que reconhecem ou não o patrimônio histórico ali apresentado e acabam por virar um local de visitação passiva. Podemos identificar o conceito de museu integral e comunitário quando o autor afirma que os visitantes precisam se reconhecer na exposição para legitima-la, pois faz-se necessário articular a memória com as demandas sociais da comunidade, no caso, a comunidade universitária. Se a exposição possui valor para a comunidade, ela atua como um espaço formativo dos sujeitos no melhor sentido freireano. As ações educativas partem do pressuposto de que o conhecimento não está pronto e inerte, e sim em constante transformação, contínuo, buscando a autonomia e novas leituras de mundo.

Por outra trajetória, Buchmann (2014) trata do fazer docente como ação política na escola e no museu. Em seu texto "Escolares nos museus: ensaio do novo público como ato político de educadores intelectuais", defende que o ensino artístico na escola deve integrar a prática docente como ação política que mediará a relação 
DOI: $10.12957 / \mathrm{e}-\mathrm{mosaicos} .2019 .41203$

estudante-museu. Além disso, o autor sugere que professores explorem de forma intencional as diversas possibilidades de ensino que o museu oferece, tornando-se os sujeitos responsáveis por mediar o conhecimento de sala de aula com a experiência vivida pelos estudantes nas exposições. Aliás, as mostras, nos lembra Waldisa Rússio em Bruno (2010) não são neutras, assim como quem as faz, pois toda ação museológica é permeada pelo ideológico, carregada de intenções. Buchmann (2014) relata que após superadas as questões precedentes ao dia da visita que os professores têm de lidar, como convencer a direção e os colegas da importância da saída, a organização da turma e do transporte, é o momento dos docentes se afirmarem como sujeitos críticos e intelectuais que têm a responsabilidade de questionar a hegemonia da alta cultura (BOURDIEU; DARBEL, 2003) excessivamente excludente, que separa o mundo público, exemplificado pelo museu, e o mundo privado da maioria dos estudantes.

A escola, para o pesquisador, é o meio para o diálogo entre o público e o privado, para o ensaio do estudante com o a sociedade. Portanto, as aulas preparatórias à visita ao museu são fundamentais, porque, ao relacionar os conteúdos escolares com o museu, faz-se uma espécie de ensaio público de autonomia, que é simbólico e político, amparado pela escola, entre o eu e o mundo. Em seu texto, o autor privilegia o fazer docente como condutor de seus estudantes para que possam, no museu e na vida, compreenderem-se como sujeitos que apropriados de suas realidades, sempre em construção, para que possam transformá-las, ou ao menos, ensaiar a transformação no espaço do museu (FREIRE, 1988, 1996; SANTOS, 2002).

Já Braga (2015), que também se debruça sobre a prática docente, analisa em seu artigo como o museu pode servir de instrumento pedagógico para professores de história da educação básica. A estratégia adotada foi visitar o Museu de Artes e Ofício (MAO) de Belo Horizonte acompanhado de docentes, estabelecendo diálogo com os professores sobre as narrativas históricas produzidas pelo museu e os usos educativos utilizados pelos docentes. $O$ autor conclui que as mostras históricas do Museu de Artes e Ofícios (MAO) são algumas das muitas possíveis representações da história ensinada em sala de aula. Os professores, segundo o autor fazem uso das exposições de forma crítica como modo de concretizar o conteúdo escolar, como uma experiência que, através do visual e da materialidade, expando o aprendizado para além do livro didático. Entretanto, a ida ao museu se anula se não houver intencionalidade, a qual é fundamental para que o uso de exposições como recurso pedagógico para o ensino de história seja significativo para os estudantes, a fim de que os mesmos possam estabelecer conexões com o conteúdo escolar de forma crítica, vislumbrando as exposições históricas como uma reflexão, entre tantas outras, sobre as várias formas de narrar e representar a história.

Por outro lado, Vergara (2016), por sua vez, nos relata o processo de criação de materiais auxiliares para fins de educação patrimonial, no Laboratório de Educação para o Patrimônio (LEP), na cidade de Pelotas, RS. A autora entende a 
DOI: $10.12957 / \mathrm{e}-\mathrm{mosaicos} .2019 .41203$

ação educativa como função principal de uma instituição museal, que realiza o exercício de comunicação entre museu e seu público, e pode fazer uso de estratégias educativas como o emprego de jogos para gerar aprendizado, valorização e respeito pelo patrimônio cultural local. A partir da observação dos interesses locais e de uma coleção de materiais educativos de outras instituições que compõem a midiateca do LEP, estudantes do curso de Museologia da Universidade Federal de Pelotas (UFPel) criaram jogos como quebra-cabeças, imagens de edificações para colorir, jogo de cartas que, pela via da ludicidade, têm potencial de valorizar o patrimônio e fortificar as relações entre a comunidade e a cidade. Nessa pesquisa, ao fazer uso de jogos, os bens patrimoniais no centro histórico de Pelotas como a Praça Coronel Pedro Osório e o Museu do Doce, são reconhecidos e se valorizam, expandindo o espaço educativo do museu.

Dessa forma, as ações educativas realizadas pelo LEP são vistas como importante auxiliares no reconhecimento e na estima de bens culturais da cidade quando aproximam deles o público de forma lúdica e desvinculada do ensino formal.

\section{CONSIDERAÇÕES FINAIS}

Dos artigos analisados, a costura que existe entre eles é dada pela noção de espaço museológico enquanto espaço educativo. Alguns autores como Oliveira (2013), Freitas e Siman (2015) e Pacheco (2010) mergulham na genealogia do museu com função social a partir da Nova Museologia e do pensamento de Paulo Freire. Outros pesquisadores refletem sobre o museu como espaço educativo que vai somar ao ensino escolar e o papel do docente deslocado da escola, tal como articulam Braga (2015) e Buchmann (2014). Por fim, Vergara (2016) traz o relato de uma visão educativa do museu para além do seu espaço físico, refletindo sobre o patrimônio urbano e as ações educativas não-formais desenvolvidas por meio de jogos para a valorização dos bens culturais da cidade de Pelotas, RS.

Podemos concluir que as pesquisas recentes aqui abordadas têm duas direções complementares. A primeira, ao investigar possibilidades de tornar o museu mais social, menos elitizado por meio da Nova Museologia, faz esforços para desenvolver espaços museológicos mais democráticos. $\mathrm{O}$ segundo caminho concentra-se no museu como complemento à educação escolar, com vistas a conhecer outras formas de narrar histórias, de relação com o patrimônio cultural. Portanto, existe um movimento, mesmo que pequeno, de compreender o museu na escola e a escola no museu (com seus processos educativos mediados por objetos). É salutar o empenho dos pesquisadores em estudar e analisar questões pertinentes à educação contemporânea inspirados por Paulo Freire, pela Nova Museologia, pelas relações sociais estabelecidas e pela vontade de transformar o status quo. A relevância das pesquisas sobre o tema contribui para o entendimento da relação de interdependência do museu com a educação e ainda sugerem muitas outras possibilidades a serem desenvolvidas. Porém, destaca-se que ainda são poucas as pesquisas em língua portuguesa que abordam a temática. 
Se hoje testemunhamos um retorno aos tempos obscuros de sujeição e dominação cultural, enquanto educadores, devemos buscar alternativas e pensar novas formas de ensinar e aprender com vistas à liberdade, ou ao menos, à consciência do status quo. A relação próxima com instituições museológicas pode nos dar fôlego para que resistamos à hegemonia que sobrepõe os interesses econômicos à educação e à cultura, como um meio para buscarmos uma educação integral.

\section{REFERÊNCIAS}

ALVES, Vânia M.S.; REIS, Maria A.G.S. Tecendo relações entre as reflexões de Paulo Freire e a mesa-redonda de Santiago do Chile, 1972. Revista Museologia e Patrimônio, Vol. 6, No 1 (2013). p. 113 - 134. Disponível em: < http://revistamuseologiaepatrimonio.mast.br/index.php/ppgpmus/article/view/253 > Acesso em: 21 Nov. 2018.

BOURDIEU, Pierre; DARBEL, Alain. O amor pela arte: os museus de arte na Europa e seu público. São Paulo: Zouk, 2003.

BRAGA, Jezulino Lúcio Mendes. Narrativas museais: diálogos possíveis entre a história pública, acadêmica e ensinada (Dossiê: Gestão, Educação e Patrimônio Cultural). e-hum, [S.I.], v. 7, n. 2, jun 2015. p. 107-115. Disponível em: <http://revistas.unibh.br/index.php/dchla/article/view/1528>. Acesso em: 05 Jan. 2019.

BRUNO, Maria Cristina Oliveira (org.). Waldisa Rússio Camargo Guarnieri: textos e contextos de uma trajetória profissional. São Paulo: Pinacoteca do Estado: Secretaria de Estado da Cultura: Comitê Brasileiro do Conselho Internacional de Museus, 2010.

BUCHMANN, Luciano Parreira. Escolares nos museus: Ensaio do novo público como ato político de educadores intelectuais. Midas [Online], 3 | 2014. Disponível em: < http://journals.openedition.org/midas/463 >. Acesso em: 05 jan 2019.

CURY, Marília Xavier. Educação em museus: panorama, dilemas e algumas ponderações. Ensino em Re-Vista, v. 20, n. 1, jan/jun 2013. p. 13-28.

.Disponível em:

$<$ https://bell.unochapeco.edu.br/revistas/index.php/rcc/article/view/2271 > Acesso em: 12 nov 2018.

DESVALLÉES, André; MAIRESSE, François. Conceitos-chave de Museologia. Tradução: Bruno Brulon Soares, Marília Xavier Cury. ICOM: São Paulo, 2013. 
FREIRE, Paulo. Pedagogia da Autonomia. Rio de Janeiro: Paz e Terra, 1996. . Pedagogia do Oprimido. Rio de Janeiro: Paz e Terra, 1988.

FREITAS, Kelly Amaral; SIMAN, Lana Mara de Castro. O MUSEU DOS QUILOMBOS E FAVELAS URBANOS NO MOVIMENTO DA DEMOCRATIZAÇÃO DOS MUSEUS (DoSsiê: Gestão, Educação e Patrimônio Cultural). e-hum, [S.I.], v. 7, n. 2, jun 2015. p. 116120. Disponível em: <http://revistas.unibh.br/index.php/dchla/article/view/1521>. Acesso em: 05 jan 2019.

OLIVEIRA, Genoveva. O museu como um instrumento de reflexão social. MIDAS [Online], 2 | 2013. Disponível em: < http://journals.openedition.org/midas/222>. Acesso em: 05 jan 2019.

PACHECO, Ricardo de Aguiar. Educação, memória e patrimônio: ações educativas em museu e o ensino de história. Rev. Bras. Hist., São Paulo, v.30, n.60, 2010. p.143154. Disponível em: < http://www.scielo.br/scielo.php?script=sci arttext\&pid=S0102$\underline{01882010000200008 \& \operatorname{lng}=e n \& n r m=i s o}>$. Acesso em: 04 jan 2019.

PEREIRA, Júnia Sales; CARVALHO, Marcus Vinicius Corrêa. Sentidos dos tempos na relação museu/escola. Caderno CEDES, Campinas, v. 30, n. 82, dez 2010. p. 383396. Disponível em: >http://www.scielo.br/scielo.php?script=sci arttext\&pid=S0101-

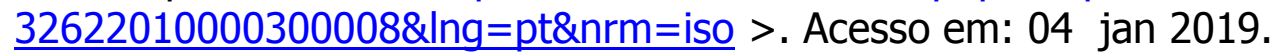

RANGEL, Vera. Porto Alegre - patrimônio ao alcance do cidadão. In: GUIMARAENS, C.; RANGEL, V.; BERTOTTO, M. (Orgs.). Museologia Social e Cultural. Rio de Janeiro: Editora Riobooks/FAPERJ, 2015.

SANTOS, Maria Célia Teixeira Moura. Museu e Educação: conceitos e métodos. Ciências e Letras: Porto Alegre, v. 31, 2002.

VERGARA, Ildaiane Pintanela. Brincando para Lembrar, Memória e Patrimônio na Contemporaneidade. RELACult - Revista Latino-Americana de Estudos em Cultura e Sociedade, [S.I.], v. 2, n. 1, mar 2016. p. 102-105. Disponível em: <http://periodicos.claec.org/index.php/relacult/article/view/52>. Acesso em: $30 \mathrm{dez}$ 2018.

Recebido em 30 de março de 2019. Aceito em 17 de junho de 2019. 
DOI: $10.12957 /$ e-mosaicos.2019.41203

Licença Creative Commons - Atribuição-NãoComercial 4.0 Internacional.

Os direitos autorais de todos os trabalhos publicados na revista pertencem ao(s) seu(s) autor(es) e coautor(es), com o direito de primeira publicação cedido à e-Mosaicos.

Os artigos publicados são de acesso público, de uso gratuito, com atribuição de autoria obrigatória, para aplicações de finalidade educacional e não-comercial, de acordo com o modelo de licenciamento Creative Commons adotado pela revista. 